\title{
High-frequency ecological momentary assessment of emotional and interpersonal states preceding and following self-injury in female adolescents
}

\author{
Julian Koenig ${ }^{1,2}$. Julia Klier ${ }^{3}$ Peter Parzer ${ }^{3} \cdot$ Philip Santangelo $^{4}$. Franz Resch ${ }^{3}$. Ulrich Ebner-Priemer ${ }^{4}$. \\ Michael Kaess ${ }^{1,5}$
}

Received: 26 February 2020 / Accepted: 19 August 2020 / Published online: 29 August 2020

(c) The Author(s) 2020

\begin{abstract}
Non-suicidal self-injury (NSSI) is a considerable health problem among adolescents. Affect regulation by means of self-injury may promote the maintenance of NSSI. However, existing findings have limited ecological validity. The present study aimed to assess emotional and interpersonal states preceding and following incidents of NSSI in female adolescents. Adolescents with NSSI-disorder completed ecological momentary assessments of affective and interpersonal states on an hourly basis for multiple days. Multilevel mixed-effect regression analyses were conducted to assess antecedences and consequences of acts of self-injury. Data from $n=73$ female adolescents covering a total of 52 acts of self-injury were available for analyses. The urge to self-injure on the between subject-level and negative affect on the within-level were best predictors of selfinjury. Surprisingly, self-injury increased negative affect and decreased feelings of attachment (mother only) in the following hour. In line with findings in adults, results illustrate the important association between negative affect and self-injury in female adolescents. However, the occurrence of NSSI itself was related to concurrent increases in negative affect, and even prospectively predicted a consecutive increase in negative affect. Therefore, improvements of negative affect following (or during) self-injury, as previously reported, are at best short-lived $(<1 \mathrm{~h})$.
\end{abstract}

Keywords Adolescents $\cdot$ Self-injury $\cdot$ Ecological momentary assessment $\cdot$ Negative affect

\section{Introduction}

Michael Kaess

michael.kaess@upd.ch

1 University Hospital of Child and Adolescent Psychiatry and Psychotherapy, University of Bern, Bern, Switzerland

2 Section for Experimental Child and Adolescent Psychiatry, Department of Child and Adolescent Psychiatry, Centre for Psychosocial Medicine, University of Heidelberg, Heidelberg, Germany

3 Clinic for Child and Adolescent Psychiatry, Centre for Psychosocial Medicine, University of Heidelberg, Heidelberg, Germany

4 Chair of Applied Psychology/Mental mHealth Lab, Institute of Sport and Sports Science, Karlsruhe Institute of Technology, Karlsruhe, Germany

5 Section for Translational Psychobiology in Child and Adolescent Psychiatry, Department of Child and Adolescent Psychiatry, Centre for Psychosocial Medicine, University of Heidelberg, Heidelberg, Germany
Self-injurious behavior (i.e., cutting, burning) is a serious problem among adolescents. Non-suicidal self-injury (NSSI) has been introduced in the 5th version of the Statistical and Diagnostic Manual of Mental Disorders (DSM-5) under section 3, as a disorder warranting further research. NSSI often occurs in the context of psychiatric conditions (such as depression), and is considered a key feature of the borderline personality disorder (BPD). The prevalence for single events of NSSI in non-clinical samples according to a recent meta-analysis is $17.2 \%$ among adolescents, $13.4 \%$ among young adults, and 5.5\% among adults [1]. The prevalence of NSSI disorder (according to DSM-5 diagnostic criteria) is estimated at 5\% among non-clinical samples of adolescents, and rates between 50 and $80 \%$ among in-patient samples are reported [2-4]. Given its prevalence, the World Health Organization has recognized NSSI as one of the top five major health threats to adolescents. Previous NSSI increases the risk for future NSSI $[5,6]$ and it has repeatedly been 
shown that NSSI predicts future suicide attempts [5-9]. NSSI is associated with greater mortality [10] and increased risk for suicide, even 15 years later [11, 12].

Whereas reasons to engage in NSSI are manifold, functions of NSSI are best described as two-factorial, constituting of two conceptually distinguishable constructs: (1) intrapersonal functions (i.e., affect regulation), and (2) social functions (i.e., interpersonal influence) [13]. This two-factor structure has been found across samples (adolescents, young adults, adults) and settings (university, clinical), [14, 15] suggesting that it probably generalizes to diverse populations [13]. Based on self-report measures, NSSI is associated with difficulties in emotion regulation [16] and youth engaging in NSSI report greater emotion reactivity [17]. NSSI occurs during states of intense negative affect and-based on selfreports-is capable to (momentarily) reduce negative affect [18]. NSSI in adolescents is most frequently performed as dysfunctional strategy to regulate intense emotions, in particular to reduce negative affect [19]. For example, in a community sample of adolescents $(n=663,57 \%$ female, $15.5 \pm 1 \cdot 18$ years), including $n=293$ adolescents endorsing NSSI in the past year $(12.87 \pm 29.4$ incidents of self-injury in the past year), intra- and interpersonal functions, such as 'to try to get a reaction from someone', 'to get control of a situation', and 'to stop bad feelings', were most common reasons to engage in self-injury [20]. Decreased negative affect following acts of NSSI may promote maintenance of NSSI and has been linked to more life-time acts of NSSI [21].

Studies using structured interviews or self-reports to address the functions of self-injury support an affect-regulating function of self-injury. Studying a sample of $n=39$ self-injurers (77\% female, $19.4 \pm 2.4$ years, $17.2 \pm 13.2$ lifetime incidents of self-injury), Klonsky reported that participants indicated that self-injury was associated with improvements in affective valence and decreases in affective arousal. Participants reported to "feel overwhelmed, sad, and frustrated before self-injury, and relieved and calm after self-injury" [22]. Experimental studies, addressing changes in momentary affect following experimental pain induction, in patients with BPD or those engaging in self-injury, seem to confirm the affect regulating function of NSSI. Recently, we have shown that adolescents engaging in NSSI report improved mood after experimental stimulation with cold pain [23]. Findings are in line with neuroimaging research in adults with BPD, suggesting amygdala deactivation as neural mechanism underlying pain-mediated affect regulation [24-26].

Studies based on retrospective interviews or self-reports are limited to address changes in affective states preceding and following actual acts of self-injury. Similar, experimental laboratory-based studies have limited ecological validity, given the experimental setting and type of pain induction (i.e., experimenter based). The aim of the present study was to address changes in momentary affect and interpersonal attachment preceding and following actual incidents of self-injury in adolescents engaging in NSSI using Ecological Momentary Assessment (EMA). By enabling repeated assessments of momentary states, EMA is well suited to track symptom dynamics and within-person processes over time in everyday life. Accordingly, EMA is well suited to investigate unstable symptomatology, such as affective states [27-30].

Previous EMA studies in adults attempted to study predictors of self-injury based on affective states. However, frequently studies were limited by an insufficient sampling frequency. High-frequency EMA is capable to capture short-lived dynamics that may be missed by lower sampling frequencies (for an example see [31]). Ammermann et al. assessed levels of positive and negative affect in adults with BPD and comorbid depression using EMA across 7 days, with four daily assessments [32]. Andrewes et al. [33] used EMA to study motives of NSSI in a sample of youth (15-25 years) with BPD ( $n=24 ; 52$ actual NSSI events). Again, EMA was limited to six daily assessments across 6 days (also see [34]).

Other studies, like those by Anestis et al. [35, 36] investigated the course of NSSI incidents over 2 weeks in $n=127$ (100\% females, $25.34 \pm 7.71$ years) using EMA (6 prompts per day, semi-random). Armey et al. [37] studied $n=36$ individuals ( $75 \%$ female, $18.70 \pm 0.79$ years) with lifetime NSSI using EMA ( 7 days, 6 random prompts per day, 10 am to $10 \mathrm{pm}, n=17$ incidents). Detectable changes in affect were reported $8 \mathrm{~h}$ before NSSI, but the random-sampling strategy prohibited detailed analyses of affect immediately before and after actual NSSI. Bresin et al. [38] used EMA to study self-injury in a college-based sample of $n=67$ (57\% female, $19.58 \pm 2.94$ years) with lifetime self-injury (median 15 lifetime NSSI events, range 1-1000). EMA (14 days, 1 retrospective assessment of the day in the evening) was based on 74 events. Muehlenkamp et al. studied positive and negative affect in $n=131$ (100\% female, $25.3 \pm 7.6$ years) bulimia patients, including $n=19$ reporting at least one event of NSSI during the EMA (14 days, event-contingent, 55 total events of NSSI). Nock et al. [40] studied 30 adolescents and young adults ( $87 \%$ female, $17.3 \pm 1.9$ years) with NSSI thoughts in the past 2 weeks $(113.4 \pm 174.9$ episodes of NSSI in the past year) using EMA (14-day period, average $17.2 \pm 5.3$ days, 2 prompts per day, 104 incidents of NSSI). In a recent study, reporting on an overlapping sample [41], Vansteelandt et al. [42] studied $n=32$ patients ( $84 \%$ female, $28 \pm 9$ years) with BPD of which $n=31$ were included in the EMA analyses ( 8 days, 10 random prompts per day, mean interval $80 \mathrm{~min}$ ).

Reviewing the existing literature reveals that existing studies predominantly focused on adults. Only studies by Nock et al. [40], Kranzler et al. [43], Andrews et al. [33, 34], and 
Armey et al. [37] included adolescents. Armey et al. included college students with lifetime NSSI and relied on a relatively small number of actual NSSI incidents $(n=17)$. The study by Nock et al. [40] included adolescents with high-frequent NSSI in the past year and analyses were based on a reasonable number of incidents ( $n=104)$, however, the sampling frequency (two prompts per day) was too low to address immediate changes in affect preceding or following NSSI. Studies by Andrews et al. $[33,34]$ were among the few including actual treatment seeking patients, based on $n=24$ patients reporting a total of 52 acts of NSSI, but again EMA was based on a relative low sampling frequency ( 6 prompts per day). The study by Kranzler et al. [43] included $n=47$ adolescents and young adults, monitored for two weeks, reporting a total of 145 episodes of NSSI. However, again sampling frequency was low ( 5 random prompts per day).

Only high-frequency EMA is capable to capture immediate effects of NSSI and acute changes in affective state preceding the behavior. Given the link between impulsivity and NSSI [44, 45] and the possibility that acts of NSSI may be spontaneously initiated, capturing these fast dynamics seems key to gain a better understanding of NSSI. Importantly, previous studies most frequently focused on affect only and not interpersonal factors such as attachment. As mentioned above, motives to engage in NSSI may be driven by intrapersonal factors (i.e., intrapersonal affect regulation) and (2) social factors (i.e., interpersonal regulation of attachment) [46]. We have previously demonstrated instability in feelings of attachment towards significant others (i.e., mother and best friend) in adolescents engaging in NSSI [47]. Therefore, alongside momentary affect, we were interested to see, how changes in feelings of momentary attachment would predict acts of NSSI.

\section{Aims of the study}

Overcoming the limitations of existing research, we aimed to address affective and interpersonal states preceding and following NSSI in female adolescents with NSSI-disorder using hourly high-frequency sampled EMA. In line with previous findings summarized above, it was hypothesized that negative affect would be increased preceding NSSI and would be decreased following NSSI. It was hypothesized that feelings of attachment towards the mother and best friend would reveal similar patterns (i.e., decreased attachment prior to NSSI).

\section{Methods}

Data for the present analysis were pooled among different EMA studies including female adolescents with NSSI disorder using the same EMA assessments conducted at the
Department of Child and Adolescent Psychiatry, Heidelberg University. The authors assert that all procedures contributing to this work comply with the ethical standards of the relevant national and institutional committees on human experimentation and with the Helsinki Declaration of 1975, as revised in 2013. All procedures involving human subjects/patients were approved by the ethics committee of the Medical Faculty at Heidelberg University (Approval Number: S-448/2014). All participants and their legal guardians signed written informed consent prior to participation in the studies. NSSI is commonly associated with both suicidal ideation and behavior [5-9]; thus, it is important to note that all clinical participants were recruited from our outpatient program, which includes particularly rigorous crisis planning and unlimited access to all levels of care within our clinic, in the case of suicidality during data collection.

All patients underwent structured clinical interviews including the Self-Injurious Thoughts and Behavior Interview (SITBI-G) [48], the borderline personality disorder part of the German version of the Structured Clinical Interview for DSM-IV Personality Disorders (SCID-II) [49], and the Mini-International Neuropsychiatric Interview for Children and Adolescents (M.I.N.I-KID 6.0) [50].

\section{Ecological momentary assessment}

After completing diagnostic assessments, female participants received a study smartphone with the movisensXS experience sampling app (Movisens $\mathrm{GmbH}$, Karlsruhe, Germany). movisensXS enables the programming of smartphones to function as electronic diaries. All participants were instructed and trained regarding the use of the smartphones and corresponding app. EMA assessments started the weekend following the handout of smartphones. Given that smartphone use is prohibited in regional schools, assessment days were limited to weekends (Saturdays and Sundays). Depending on the study, participants carried the e-diary on one or two consecutive weekends, i.e., on a total of 2 or 4 days. The movisensXS app emitted an acoustic prompting signal according to a random time-sampling schedule on average once per hour (i.e., in $60 \mathrm{~min}$ intervals) with a target number of 12 assessments per subject per day. Prompting signals started at $10 \mathrm{am}$ and finished regularly at $10 \mathrm{pm}$. To maximize compliance and to increase the probability to obtain 12 assessments per participant per day, participants were enabled to postpone up to 2 alarms that were amended on the respective day (prompts finishing at midnight). Each completed response was automatically time-stamped by the app. Data were assessed, uploaded and stored pseudonymized and encrypted on both devices and movisens servers. After completing the assessments participants returned the smartphones, were debriefed and financially 
compensated. Participants received 12 Euros for taking part in the diagnostic assessments and 1 Euro for every completed assessment, given a minimum of $50 \%$ completed prompts.

At each prompt, participants were asked a number of questions. First, participants were instructed to rate their momentary affect and current attachment towards significant others (mother and best friend). Current affective states were assessed based on a four item short-form of the Multidimensional Mood Questionnaire designed for the usage in EMA studies [51]. Participants responded to the statement "At this moment I feel..." by means of four bipolar items (two positively poled items: unwell-well, agitated-calm; and two negatively poled items: content-discontent, relaxed-tense). Participants rated each item on a visual analog scale [VAS] ranging from 0 to 100 . These items have shown both very good psychometric properties and good sensitivity to change [51]. Next, participants were asked to indicate whether they engaged in dysfunctional behavior within the past hour since the preceding assessment. Participants had the option to endorse the following responses (multiple responses possible): no, high-risk behavior; cutting, scratching, burning; hitting head against the wall; sexual impulsive behavior; alcohol, drugs, pills; binge eating, vomiting; other. Next, participants were asked to indicate whether they engaged in any distracting behavior since the preceding assessment (within the past hour did you engage in any of the following activities to distract yourself). Participants had the option to endorse the following responses (multiple responses possible): no, no distraction; homework/learning; watching TV/playing video games; meeting with friends; sports; relaxing/sleeping; other/other distraction. Next, participants were asked to rate their current urge to self-injure on a VAS ranging from 0 to 100 ("At this moment, how strong is your urge to self-injure?"). Finally, to assess participants' current interpersonal states four items addressing the momentary attachment to the participant's mother and four items regarding the momentary attachment to the best friend (named in the first assessment during the training session) were used. Items assessing momentary interpersonal states were worded as: (1) How close do you feel to your mother/best friend right now?; (2) How important is your mother/best friend to you right now?; (3) What do you think, how close does your mother/best friend feel to you right now?; (4) What do you think, how important are you for your mother/best friend right now? Participants rated each item on VAS ranging from 0 to 100 . Beyond good compliance, the respective EMA methodology showed reliability and validity in our previous studies, as evidenced by correlations of EMA-derived measures with clinical interviews [47].

\section{Data preprocessing and analyses}

For the present analyses endorsements of cutting, scratching, and burning were recorded as events of self-injury. Any endorsement of any distracting activity was coded as distraction. Analyses focused on $\pm 1 \mathrm{~h}$ surrounding actual reports of self-injury. A composite negative affect score was created by invers scoring the two positively poled items and then calculating the mean value of the four affect items for each assessment. Possible values of the mean scores range from 0 to 100 , with a higher score corresponding to a greater negative affective state. Two attachment scores (mother and best friend) were created by calculating the mean value of the respective four attachment items for each administration of the scale. Possible values of these mean scores range from 0 to 100 , with higher scores corresponding to greater levels of momentary attachment. Scores were standardized to distinguish within from between effects on different levels of analyses. First, scores were $z$-standardized across all assessments (independent of subject and day) to enhance comparability of regression coefficients (termed: global-level). Second, the mean for each subject was calculated and subtracted from the standardized score (termed: subject-level). Third, the mean of each day for each subject was calculated. To achieve a pure within-subject and day predictor, the mean for each day of assessment for each subject was subtracted from the standardized score (termed: within-level).

First, multilevel mixed-effects logistic regressions with robust variance estimation predicting self-injury by the (M1) urge to self-injure, (M2) negative affect and (M3) interpersonal attachment (mother and best friend) preceding reported acts of self-injury were calculated for each within and between effect (global-, subject-, and within-level). The subject ID and day of assessment within subjects were included as random effects to control for interpersonal differences and differences between different days of assessments in all models. Concrete, the respective models predicted the likelihood of NSSI, based on ratings on the urge to selfinjure, negative affect and interpersonal attachment (mother and best friend) preceding actual self-injury in contrast to ratings not preceding self-injury adjusted for differences between individuals and day of assessment. First, single models for each predictor (urge to self-inure, negative affect, attachment towards mother, attachment toward best friend) were calculated, followed a stepwise logistic regression minimizing the Bayes Information Criterion [BIC]. Predictors that survived the stepwise regression were subjected to further analyses, addressing their interaction with distracting activities in mixed-effects logistic regressions with robust variance estimation.

Second, to address consequences of self-injury on the urge to self-injure, negative affect, and interpersonal attachment (mother and best friend), mixed-effects regression 
with robust variance estimation were calculated predicting change in the aforementioned variables based on self-injury. Successive differences scores were calculated for the urge

Table 1 Clinical and Sociodemographic Characteristics of the Sample; ICD-10 diagnoses: multiple diagnoses possible; BPD: borderline personality disorder based on SCID interview; NSSI frequency based on SITBI interview; school: after four years of elementary school the German school system branches into three types of secondary schools. The so called Hauptschule (Secondary General School which takes five years after Primary School) prepares pupils for vocational training, whereas the Realschule (Intermediate Secondary School) concludes with a general certificate of secondary education after six years. Eight years of Gymnasium provide pupils with a general university entrance qualification

\begin{tabular}{lc}
\hline$N$ (female) & $73(73)$ \\
Age, mean (SD) & $15.48(1.19)$ \\
School, $n(\%)$ & \\
Hauptschule & $4(5.48)$ \\
Realschule & $28(38.36)$ \\
Gymnasium & $28(38.36)$ \\
Other & $13(17.8)$ \\
ICD-10 diagnoses, $n(\%)$ & \\
F1 & $21(28.77)$ \\
F2 & $1(1.37)$ \\
F3 & $49(67.12)$ \\
F4 & $39(53.42)$ \\
F5 & $11(15.07)$ \\
F6 & $24(32.88)$ \\
F9 & $14(19.18)$ \\
NSSI frequency past year, mean (SD) & $104.88(117.99)$ \\
BPD, $n(\%)$ & $41(56.16)$ \\
BPD criteria, mean (SD) & $4.68(2.04)$ \\
\hline
\end{tabular}

to self-injure, negative affect and interpersonal attachment, each between two adjacent assessments. Events of selfinjury (yes/no) were included as fixed effect. Again, ID and the assessment day within ID were included as random effects to control for inter-day and inter-person variability. All analyses were conducted in Stata/SE (15.0, Stata Corp LLC, College Station, TX, USA), at an alpha level of 0.05.

\section{Results}

\section{Pooled data and study sample}

Data from a total of $n=73$ female adolescents were available for analyses. Adolescents participated in various studies including the same EMA at the Department of Child and Adolescent Psychiatry in Heidelberg. Samples included case-control data that were previously published [47] and data from ongoing treatment studies, using pre-treatment assessments only. Given the event-related nature of the planned analyses, data from all subjects were pooled. Sociodemographic and clinical characteristics of the sample are provided in Table 1. On average, participants completed 3 days of EMA with an average of $9.73(\mathrm{SD}=3.04)$ daily assessments. The entire sample comprised a total of $n=2131$ observations (hourly assessments). Actual acts of self-injury during EMA were reported by $n=20$ patients with an average frequency of $2.60(\mathrm{SD}=2.48$; range $1-11)$. A total of 52 acts of self-injury were available for analyses $(2.44 \%$ of total observations). Acts of self-injury were reported independent of the time of day, with the majority of events occurring in the evening as illustrated in Fig. 1.
Fig. 1 Acts of self-injury by time of day; percentage values relative to the total acts of self-injury recorded $(n=52)$; $A M$ EMA was conducted from 9 AM till midday, $P M$ EMA was conducted from 1 PM till midnight, $\%$ relative percentage of NSSI reported within the specific hour based on a total of $n=52$ actual acts of NSSI
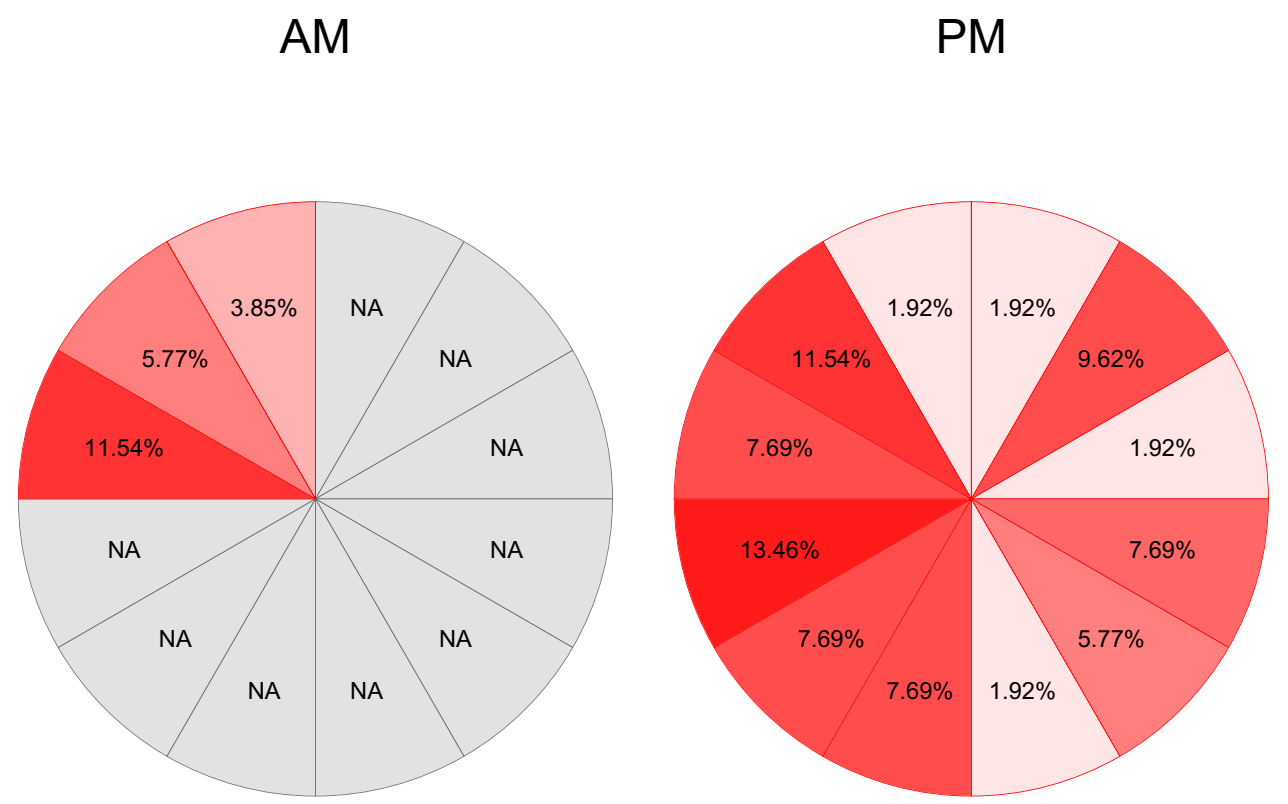


\section{Momentary predictors of self-injury}

The urge to self-injure predicted actual self-injury in the following hour on the global (OR: 1.63, 95\% CI [1.04; 2.55]) and subject-level (OR: 5.99, 95\% CI [2.30; 15.58]), but was not predictive on the within-level (OR: $3.79,95 \% \mathrm{CI}$ $[0.78 ; 18.44])$. Greater negative affect was associated with an increased likelihood to report self-injury in the following hour on the global (OR: $1.83,95 \%$ CI $[1.11 ; 3.02])$, subject- (OR: 10.39, 95\% CI [2.29; 47.12]), and within-level (OR: 16.42, 95\% CI [4.82; 55.93]). Feelings of attachment towards the mother, were only predictive for self-injury on the subject-level (OR: $0.39,95 \%$ CI $[0.16 ; 0.96]$ ), such that greater attachment was associated with a lower likelihood of actual self-injury. Feelings of attachment towards the best friend were only predictive for self-injury on the within-level (OR: $0.27,95 \%$ CI [0.08; 0.94]) such that greater attachment was associated with a lower likelihood of self-injury. In multiple regression analyses including all predictors, only the urge to self-injure on the subject-level (OR: 3.62, 95\% CI $[1.10 ; 11.91])$, negative affect on the global- (OR: 1.77, 95\% CI $[1.15 ; 2.73]$ ) and within-level (OR: 23.11, 95\% CI $[1.66 ; 322.75])$, as well as attachment towards the mother on the subject-level (OR: $0.29,95 \%$ CI $[0.12 ; 0.70]$ ) were still significant after adjusting for the other predictors. Stepwise regression minimizing the $\mathrm{BIC}$ emphasized the urge to selfinjure on the subject-level (OR: 6.76, 95\% CI [2.51; 18.23]) and negative affect on the within-level (OR: 14.85, 95\% CI $[4.16 ; 53.02])$ to be the best predictors of self-injury. Findings of effects on the global-level are illustrated in Fig. 2. Reported distraction by other actives had no significant effect on actual self-injury and did not moderate the effect of negative affect (interaction distraction $\mathrm{x}$ affect: $\mathrm{OR}=1.31$, $p=0.558)$.
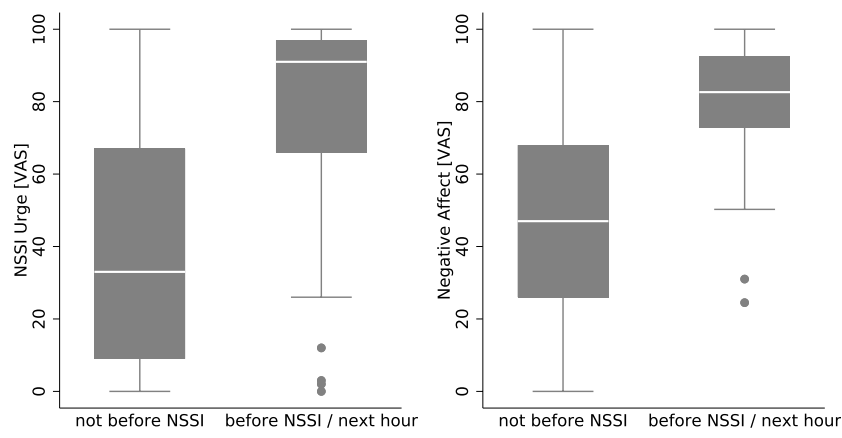

\section{Momentary consequences of self-injury}

For a total of $n=34$ acts of self-injury, there was sufficient non-missing data from assessments taken in the following hour to assess consequences of NSSI. There were a total of four cascades of NSSI (acts of self-injury reported in 2 consecutive hours on the same day of assessment), that were included in the analyses. Actual self-injury had no significant effect on the urge to self-injure $\left(\chi_{(1)}^{2}=0.82\right.$, $p=0.366)$. Interestingly, the urge to self-injure slightly increased following self-injury $(\Delta z=0.21, \mathrm{SD}=1.16)$ compared to changes in adjacent assessment without reporting of self-injury $(\Delta z=0.01, \mathrm{SD}=0.81)$. Self-injury resulted in significant increases in negative affect $\left(\chi_{(1)}^{2}=9.23\right.$, $p=0.002)$. As depicted in Fig. 3, negative affect increased ( $\Delta z=0.36, \mathrm{SD}=0.83$ ) following acts of self-injury, compared to changes in adjacent assessment without reporting of self-injury $(\Delta z=-0.005, \mathrm{SD}=0.89)$. Self-injury decreased $(\Delta z=-0.22, \mathrm{SD}=0.57)$ the attachment towards the mother $\left(\chi_{(1)}^{2}=5.18, p=0.016\right)$ compared to recordings with no reported self-injury $(\Delta z=-0.002, \mathrm{SD}=0.48)$. There were no effects of self-injury on the attachment towards the best friend $\left(\chi_{(1)}^{2}=0.64, p=0.423\right)$.

\section{Discussion}

The present study sought to identify short-term predictors and consequences of actual self-injury, addressing affective and interpersonal states in everyday life of female adolescents engaging in NSSI. Pooling of data resulted in a sample of $n=73$ female adolescents, of whom 20 reported a total of 52 acts of NSSI in high-frequency hourly EMA. Descriptive data from the study are in line with previous reports, suggesting that most frequently self-injury is conducted in the evening hours [52]. However, considering that EMA assessments were limited to the weekends, we found a surprisingly

Fig. 2 Predictors of Acts of Self-Injury; illustrated is the mean urge to self-injure (a), negative affect (b), attachment towards the mother (c) and best friend (d) before and not-before reported self-injury; VAS visual analogue scale, NSSI non-suicidal self-injury 
Fig. 3 Negative affect preceding and following self-injury; mean and $95 \%$ confidence interval of negative affect before, after and $1 \mathrm{~h}$ after acts of self-injury; $V A S$ visual analogue scale, NSSI non-suicidal self-injury

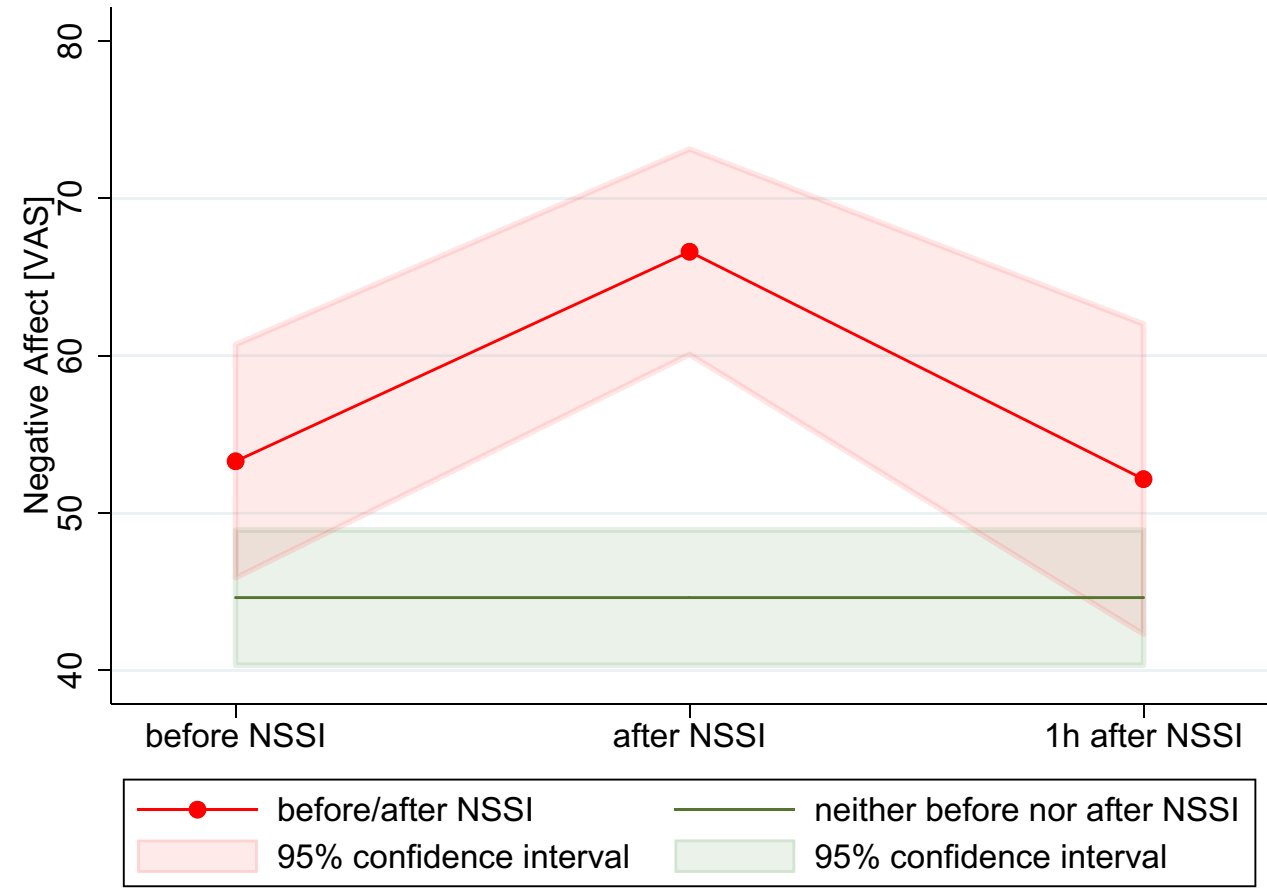

high frequency of NSSI early in the morning, i.e., in the hour preceding the first assessment at $10 \mathrm{am}$.

Addressing predictors of actual acts of self-injury, results illustrate that the urge to self-injure on the subject-level and negative affect on the within-level predicted subsequent NSSI. In line with previous research, negative affect was the strongest predictor of NSSI [41] — among those that were investigated (i.e., affect, urge, attachment towards the mother or best friend). Changes in interpersonal states, such as the felt attachment towards the mother and best friend, did not predict the likelihood of reporting self-injury in the following hour. An interesting finding is that distraction by other activities (i.e., homework, watching TV, meeting with friends, sports), did not change the predictive value of negative affect. Thus, it seems key to reduce negative affect in the first place. Based on our analyses, it seems plausible to hypothesize, that once negative affect is too high, distraction is unlikely to prevent acts of NSSI. In this regard, future studies, addressing the effect of, e.g., skills taught in treatment for NSSI, such as dialectical behavioral therapy (DBT), would be interesting. Evidence from such EMA studies could inform psychotherapeutic practice and guide the use of particular techniques to prevent acts of NSSI in times of heightened emotional distress.

Regarding the consequences of NSSI, again, the present study reveals that self-injury does not result in a decrease of negative affect in the following hour. This has previously been shown by an EMA study [41] with a time interval of $\sim 1.33 \mathrm{~h}$ between assessments, conducted in $n=30$ adult inpatients with BPD. Other studies have shown that negative affect decreases following experimentally induced pain in adolescents with NSSI [23]. Based on the present findings, it is suggested that the momentary relief is of short duration and unlike expected, NSSI actually leads to an increase of negative affect within the hour following self-injury. Thus, findings from EMA studies on adolescent NSSI using a lower sampling-frequency, illustrating a decrease in negative affect hours after actual NSSI, likely do not capture the actual increase in negative affect immediately following NSSI, but illustrate a regression to the mean after the initial increase in negative affect preceding NSSI. From a methodological viewpoint, these findings emphasize the importance of appropriate sample frequencies in EMA studies [31].

Replicating earlier findings in adults [41], the present study confirms that a potential relief from negative affect following NSSI is certainly of short duration. As previously discussed [41], this suggests that changes in affect immediately following (or during) NSSI, are capable to reinforce the behavior and that negative consequences on the time scale of hours are neglected or are not relevant concerning the maintenance of NSSI. The decrease in negative affect following self-injury, as reported by EMA studies in adults at lower sample rates (e.g., $2 \mathrm{~h}$ ), is in line with the present findings, illustrating a return of negative affect to levels comparable to those reported before self-injury, 1-2 h after NSSI [37]. However, the present findings emphasize that this decrease in negative affect is preceded by an initial increase in negative affect following NSSI.

The study has several strengths and limitations that should be addressed. In comparison to previous studies in 
adolescents and adults, we used a relatively high-frequency sampling approach based on hourly EMA, report on a large sample covering a reasonable number of actual events of self-injury and included outpatients with severe NSSI-disorder. However, analyses were still limited to $n=20$ patients reporting self-injury within EMA assessments limited to days of the weekend. Further, we only included females and findings might not generalize to male patients. We are not able to determine the actual time of self-injury (on a scale of minutes) and, accordingly, the time between self-injury and respective ratings on self-report measures. EMA studies enabling patient emitted assessments (i.e., in the event of self-injury) may help to focus on the minutes following acts of self-injury and overcome these limitations. Future studies would do well to further distinguish different qualities of negative affect in the context of NSSI. For example, it is possible that our aggregated measure of negative affect conceals differential dynamics in affect by the antagonistic states of distress and e.g., feelings of shame. As such, it is possible that NSSI decreases distress but increases shame and that such effects result in an overall increase of negative affect (umbrella term).

To conclude, the present study illustrates that the affect regulating function of NSSI in female adolescents is shortlived and that self-injury may actually increase negative affect. This finding challenges common beliefs about affect regulation in NSSI and should inform practice in clinical care (i.e., psychoeducation). Patients should be educated that the engagement in NSSI prospectively predicts an increase in negative affect. Intended effects of relieve from negative affect are at best short-lived $(<1 \mathrm{~h})$ and should be traded off against longer lasting aggravations of affective states.

Funding Open Access funding provided by Projekt DEAL. We would like to thank the Dietmar Hopp Foundation, Germany, for their funding of the "Ambulanz für Risikoverhalten und Selbstschädigung" (AtR!Sk) where our study was conducted.

\section{Compliance with ethical standards}

Conflict of interest The authors have no conflict of interest to declare.

Open Access This article is licensed under a Creative Commons Attribution 4.0 International License, which permits use, sharing, adaptation, distribution and reproduction in any medium or format, as long as you give appropriate credit to the original author(s) and the source, provide a link to the Creative Commons licence, and indicate if changes were made. The images or other third party material in this article are included in the article's Creative Commons licence, unless indicated otherwise in a credit line to the material. If material is not included in the article's Creative Commons licence and your intended use is not permitted by statutory regulation or exceeds the permitted use, you will need to obtain permission directly from the copyright holder. To view a copy of this licence, visit http://creativecommons.org/licenses/by/4.0/.

\section{References}

1. Swannell SV, Martin GE, Page A et al (2014) Prevalence of nonsuicidal self-injury in nonclinical samples: systematic review, meta-analysis and meta-regression. Suicide Life Threat Behav 44:273-303. https://doi.org/10.1111/sltb.12070

2. Zetterqvist M (2015) The DSM-5 diagnosis of nonsuicidal self-injury disorder: a review of the empirical literature. Child Adolesc Psychiatry Ment Health. https://doi.org/10.1186/s1303 4-015-0062-7

3. Plener PL, Allroggen M, Kapusta ND et al (2016) The prevalence of Nonsuicidal Self-Injury (NSSI) in a representative sample of the German population. BMC Psychiatry. https://doi.org/10.1186/ s12888-016-1060-x

4. Kaess M (2012) Selbstverletzendes Verhalten im Jugendalter. Beltz-Verlag, Weinheim

5. Asarnow JR, Porta G, Spirito A et al (2011) Suicide attempts and nonsuicidal self-injury in the treatment of resistant depression in adolescents: findings from the TORDIA study. J Am Acad Child Adolesc Psychiatry 50:772-781. https://doi.org/10.1016/j. jaac.2011.04.003

6. Wichstrøm L (2009) Predictors of non-suicidal self-injury versus attempted suicide: similar or different? Arch Suicide Res Off J Int Acad Suicide Res 13:105-122. https://doi.org/10.1080/13811 110902834992

7. Prinstein MJ, Nock MK, Simon V et al (2008) Longitudinal trajectories and predictors of adolescent suicidal ideation and attempts following inpatient hospitalization. J Consult Clin Psychol 76:92103. https://doi.org/10.1037/0022-006X.76.1.92

8. Tang J, Yu Y, Wu Y et al (2011) Association between nonsuicidal self-injuries and suicide attempts in Chinese adolescents and college students: a cross-section study. PLoS ONE 6:e17977. https://doi.org/10.1371/journal.pone.0017977

9. Wilkinson P, Kelvin R, Roberts C et al (2011) Clinical and psychosocial predictors of suicide attempts and nonsuicidal self-injury in the Adolescent Depression Antidepressants and Psychotherapy Trial (ADAPT). Am J Psychiatry 168:495-501. https://doi.org/10.1176/appi.ajp.2010.10050718

10. Hawton K, Harriss L (2007) Deliberate self-harm in young people: characteristics and subsequent mortality in a 20 -year cohort of patients presenting to hospital. J Clin Psychiatry 68:1574-1583

11. Hawton K, Zahl D, Weatherall R (2003) Suicide following deliberate self-harm: long-term follow-up of patients who presented to a general hospital. Br J Psychiatry J Ment Sci 182:537-542

12. Hawton $\mathrm{K}$, Bergen $\mathrm{H}$, Cooper $\mathbf{J}$ et al (2015) Suicide following self-harm: Findings from the Multicentre Study of self-harm in England, 2000-2012. J Affect Disord 175:147-151. https://doi. org/10.1016/j.jad.2014.12.062

13. Klonsky ED, Glenn CR, Styer DM et al (2015) The functions of nonsuicidal self-injury: converging evidence for a two-factor structure. Child Adolesc Psychiatry Ment Health. https://doi. org/10.1186/s13034-015-0073-4

14. Klonsky ED, Glenn CR (2008) Assessing the functions of nonsuicidal self-injury: psychometric properties of the inventory of statements about self-injury (ISAS). J Psychopathol Behav Assess 31:215-219. https://doi.org/10.1007/s10862-008-9107-z

15. Nock MK, Prinstein MJ (2004) A functional approach to the assessment of self-mutilative behavior. J Consult Clin Psychol 72:885-890. https://doi.org/10.1037/0022-006X.72.5.885

16. Gratz KL, Roemer L (2008) The relationship between emotion dysregulation and deliberate self-harm among female undergraduate students at an urban commuter university. Cogn Behav Ther 37:14-25. https://doi.org/10.1080/16506070701819524 
17. Nock MK, Wedig MM, Holmberg EB, Hooley JM (2008) The emotion reactivity scale: development, evaluation, and relation to self-injurious thoughts and behaviors. Behav Ther 39:107-116. https://doi.org/10.1016/j.beth.2007.05.005

18. Kamphuis JH, Ruyling SBM, Reijntjes AH (2007) Testing the emotion regulation hypothesis among self-injuring females: evidence for differences across mood states. J Nerv 195:912-918. https://doi.org/10.1097/NMD.0b013e3181593d89

19. Klonsky ED (2007) The functions of deliberate self-injury: a review of the evidence. Clin Psychol Rev 27:226-239. https:// doi.org/10.1016/j.cpr.2006.08.002

20. Lloyd-Richardson EE, Perrine N, Dierker L, Kelley ML (2007) Characteristics and functions of non-suicidal self-injury in a community sample of adolescents. Psychol Med 37:1183-1192. https ://doi.org/10.1017/S003329170700027X

21. Jenkins AL, Schmitz MF (2012) The roles of affect dysregulation and positive affect in non-suicidal self-injury. Arch Suicide Res 16:212-225. https://doi.org/10.1080/13811118.2012.695270

22. Klonsky ED (2009) The functions of self-injury in young adults who cut themselves: clarifying the evidence for affect regulation. Psychiatry Res 166:260-268. https://doi.org/10.1016/j.psych res.2008.02.008

23. Koenig J, Rinnewitz L, Warth M et al (2016) Psychobiological response to pain in female adolescents with nonsuicidal selfinjury. J Psychiatry Neurosci JPN 42:160074

24. Niedtfeld I, Schulze L, Kirsch P et al (2010) Affect regulation and pain in borderline personality disorder: a possible link to the understanding of self-injury. Biol Psychiatry 68:383-391. https ://doi.org/10.1016/j.biopsych.2010.04.015

25. Niedtfeld I, Kirsch P, Schulze L et al (2012) Functional connectivity of pain-mediated affect regulation in borderline personality disorder. PLoS ONE 7:e33293. https://doi.org/10.1371/journ al.pone.0033293

26. Niedtfeld I, Schmitt R, Winter D et al (2017) Pain-mediated affect regulation is reduced after dialectical behavior therapy in borderline personality disorder: a longitudinal fMRI study. Soc Cogn Affect Neurosci 12:739-747. https://doi.org/10.1093/scan/nsw183

27. Ebner-Priemer UW, Eid M, Kleindienst N et al (2009) Analytic strategies for understanding affective (in)stability and other dynamic processes in psychopathology. J Abnorm Psychol 118:195-202. https://doi.org/10.1037/a0014868

28. Santangelo P, Bohus M, Ebner-Priemer UW (2014) Ecological momentary assessment in borderline personality disorder: a review of recent findings and methodological challenges. J Personal Disord 28:555-576. https://doi.org/10.1521/ pedi_2012_26_067

29. Solhan MB, Trull TJ, Jahng S, Wood PK (2009) Clinical assessment of affective instability: comparing EMA indices, questionnaire reports, and retrospective recall. Psychol Assess 21:425436. https://doi.org/10.1037/a0016869

30. Trull TJ, Ebner-Priemer U (2013) Ambulatory assessment. Annu Rev Clin Psychol 9:151-176. https://doi.org/10.1146/annurevclinpsy-050212-185510

31. Kockler TD, Santangelo PS, Ebner-Priemer UW (2018) Investigating binge eating using ecological momentary assessment: the importance of an appropriate sampling frequency. Nutrients. https ://doi.org/10.3390/nu10010105

32. Ammerman BA, Olino TM, Coccaro EF, McCloskey MS (2017) Predicting nonsuicidal self-injury in borderline personality disorder using ecological momentary assessment. J Personal Disord 31:844-855. https://doi.org/10.1521/pedi_2017_31_278

33. Andrewes HE, Hulbert C, Cotton SM et al (2017) Ecological momentary assessment of nonsuicidal self-injury in youth with borderline personality disorder. Personal Disord 8:357-365. https ://doi.org/10.1037/per0000205
34. Andrewes HE, Hulbert C, Cotton SM et al (2017) An ecological momentary assessment investigation of complex and conflicting emotions in youth with borderline personality disorder. Psychiatry Res 252:102-110. https://doi.org/10.1016/j.psychres.2017.01.100

35. Anestis MD, Silva C, Lavender JM et al (2012) Predicting nonsuicidal self-injury episodes over a discrete period of time in a sample of women diagnosed with bulimia nervosa: an analysis of self-reported trait and ecological momentary assessment based affective lability and previous suicide attempts. Int J Eat Disord 45:808-811. https://doi.org/10.1002/eat.20947

36. Armey MF, Nugent NR, Crowther JH (2012) An exploratory analysis of situational affect, early life stress, and nonsuicidal selfinjury in college students. J Child Adolesc Trauma 5:327-343. https://doi.org/10.1080/19361521.2012.719594

37. Armey MF, Crowther JH, Miller IW (2011) Changes in ecological momentary assessment reported affect associated with episodes of nonsuicidal self-injury. Behav Ther 42:579-588. https://doi. org/10.1016/j.beth.2011.01.002

38. Bresin K, Carter DL, Gordon KH (2013) The relationship between trait impulsivity, negative affective states, and urge for nonsuicidal self-injury: a daily diary study. Psychiatry Res 205:227-231. https ://doi.org/10.1016/j.psychres.2012.09.033

39. Muehlenkamp JJ, Engel SG, Wadeson A et al (2009) Emotional states preceding and following acts of non-suicidal self-injury in bulimia nervosa patients. Behav Res Ther 47:83-87. https://doi. org/10.1016/j.brat.2008.10.011

40. Nock MK, Prinstein MJ, Sterba SK (2009) Revealing the form and function of self-injurious thoughts and behaviors: a real-time ecological assessment study among adolescents and young adults. J Abnorm Psychol 118:816-827. https://doi.org/10.1037/a0016 948

41. Houben M, Claes L, Vansteelandt K et al (2017) The emotion regulation function of nonsuicidal self-injury: a momentary assessment study in inpatients with borderline personality disorder features. J Abnorm Psychol 126:89-95. https://doi.org/10.1037/ abn0000229

42. Vansteelandt K, Houben M, Claes L et al (2017) The affect stabilization function of nonsuicidal self injury in borderline personality disorder: an ecological momentary assessment study. Behav Res Ther 92:41-50. https://doi.org/10.1016/j.brat.2017.02.003

43. Kranzler A, Fehling KB, Lindqvist J et al (2018) An ecological investigation of the emotional context surrounding nonsuicidal self-injurious thoughts and behaviors in adolescents and young adults. Suicide Life Threat Behav 48:149-159. https://doi. org/10.1111/sltb.12373

44. Hamza CA, Willoughby T, Heffer T (2015) Impulsivity and nonsuicidal self-injury: a review and meta-analysis. Clin Psychol Rev 38:13-24. https://doi.org/10.1016/j.cpr.2015.02.010

45. Lockwood J, Daley D, Townsend E, Sayal K (2017) Impulsivity and self-harm in adolescence: a systematic review. Eur Child Adolesc Psychiatry 26:387-402. https://doi.org/10.1007/s0078 7-016-0915-5

46. Muehlenkamp J, Brausch A, Quigley K, Whitlock J (2013) Interpersonal features and functions of nonsuicidal self-injury. Suicide Life Threat Behav 43:67-80. https://doi.org/10.1111/j.1943278X.2012.00128.x

47. Santangelo PS, Koenig J, Funke V et al (2016) Ecological momentary assessment of affective and interpersonal instability in adolescent non-suicidal self-injury. J Abnorm Child Psychol. https:// doi.org/10.1007/s10802-016-0249-2

48. Fischer G, Ameis N, Parzer P et al (2014) The German version of the self-injurious thoughts and behaviors interview (SITBI$\mathrm{G})$ : a tool to assess non-suicidal self-injury and suicidal behavior disorder. BMC Psychiatry 14:265. https://doi.org/10.1186/s1288 8-014-0265-0 
49. First M, Spitzer R, Gibbon M, Williams, (2002) Structured clinical interview for dsm-iv-tr axis i disorders, research version, nonpatient edition (SCID-I/ NP). Biometrics Research, New-York

50. Sheehan DV, Sheehan KH, Shytle RD et al (2010) Reliability and validity of the mini international neuropsychiatric interview for children and adolescents (MINI-KID). J Clin Psychiatry 71:313326. https://doi.org/10.4088/JCP.09m05305whi

51. Wilhelm P, Schoebi D (2007) Assessing mood in daily life: structural validity, sensitivity to change, and reliability of a short-scale to measure three basic dimensions of mood. Eur J Psychol Assess 23:258-267. https://doi.org/10.1027/1015-5759.23.4.258

52. Horrocks J, Price S, House A, Owens D (2003) Self-injury attendances in the accident and emergency department: clinical database study. Br J Psychiatry J Ment Sci 183:34-39 